\title{
Stress corrosion damage on austenitic stainless steel in sodium chloride
}

\author{
N. Islami, S. Rashid, A.K. Ariffin* and M.Z. Nuawi \\ Department of Mechanical and Material Engineering, Universiti Kebangsaan Malaysia, \\ 43600 Bandar Baru Bangi, Selangor Darul Ehsan, Malaysia \\ *Email: kamal3@ukm.edu.my
}

\begin{abstract}
The aim of this work is to present the corrosion damage mechanism of austenitic stainless steel 304. The C-ring specimens are chosen according to ASTM G-38 to resemble the stress conditions during the applied load. The specimens are immersed in $3.5 \% \mathrm{wt}$ of $\mathrm{NaCl}$ solution. The variable conditions were studied at a fixed stress of $379 \mathrm{Mpa}$ and immersions for 720 hours. The stress distribution over the surface of specimens is formulated by means of a finite-element analysis. The result of the finite-element analysis shows that the region that was perpendicular to the shift in the direction of the pressure was subjected to the highest load. Using the potentiodynamic polarisation measurement method and microscopic observation, the corrosion polarisation behaviour of austenitic stainless steel became more active in cases when immersion and stress are applied simultaneously. The stress on the surface of the specimen shows a significant effect on the polarisation mechanism in the analysed area. The result also shows that the locations of pitting corrosion are apparent on the highest stress area. There is useful information to analyse the corrosion behaviour especially for applications under mechanical loading in corrosive environments, it drives the corrosion behaviour to the critical condition.
\end{abstract}

Keywords: Pitting corrosion; austenitic stainless steel; stress distribution; corrosive environments.

\section{INTRODUCTION}

Stainless steels are widely used in manufacturing industries, due to their high strength and corrosion resistance in many environments [1,2]. However, austenitic stainless steels are essentially iron chromium -nickel ternary alloys containing sixteen to twenty five \% chromium and seven to twenty \% metal. These alloys area unit is referred to as austenitic since their structure remains a solid solution (FCC, $\gamma$ iron type) at all normal heat treating temperatures. The presence of the nickel, that has an associate degree FCC crystal structure, alters the FCC structure to be preserved under temperature. The high formability of the solid solution stainless-steel is due to their FCC structure. Solid solution stainless steels ordinarily have higher corrosion resistance than Ferritic and Martensitic ones as a result of the carbides being often preserved in a primary solid solution by speedy cooling from an increased temperature, the chromium imparts coating the surface with a thin but extremely dense film of chromium oxide [3]. Austenitic stainless steel is the largest and most important group in the stainless steel range. The corrosion resistance of austenitic stainless steels is attributed to the formation of a thin and self-healing 'passive film' on the surface of stainless steel [4-8]. 
The mechanical loading effects such as stress-strain, or weld heat treatment can affect the corrosion process on certain materials. Mechanical load and environment in materials / areas can begin the occurrence of corrosion and can be pointed at the initial failure. The development of the electrochemical measurement is an important tool to understand the effects of stress corrosion [9]. Such understanding is important because previous researchers who have conducted research on stress corrosion cracking (SCC) are more focused on the occurrence of corrosion cracking, the speed of corrosion on the cracking and the corrosion effects on the crack propagation. However, the passive layer is an inexpensive means of corrosion protection. Depending on the environment, it sometimes breaks down, causing severe localised corrosion attacks, such as pitting, crevice, and stress corrosion cracking, leading to catastrophic failures. Austenitic stainless steels (ASS) offer excellent corrosion resistance in many organic, acidic, industrial and marine environments but, when the passive film is destroyed in a localised area, the pitting corrosion processes could result and lead to unexpected failures [10]. The corrosion mechanism of a material is represented by a polarisation curve during the anodic and cathodic reaction. A polarisation curve is generated by the polarisation measurement based on electrochemical concepts and is allowed to determine the corrosion rate instantly [11]. Polarisation data provides the information of the corrosion behaviour of a material during the reaction.

The objective of the current paper is to illustrate that the polarisation curve is an important aspect in the corrosion analysis. The generated stress by mechanical loading will have a significant effect on the polarisation mechanism in the analysed area. There is useful information to analyse the corrosion behaviour especially for applications under mechanical loading in corrosive environments. For this reason, studies on the polarisation mechanism under mechanical loading are worth considering. This paper effort has been concentrated on the localised corrosion of austenitic stainless steel in chloride media. Austenitic stainless steel type 304 was shaped as a C-ring specimen according to the ASTM G-38 Standard. The polarisation measurements were carried out in the sodium chloride $(\mathrm{NaCl})$. Compression test were implemented to predict the relation between deflection and value of load[12]. The maximum value in the elastic zone of the C-ring specimen predicted by using compression test results. The estimation of the desired stress on the surface of the C-ring specimen was simulated using the finite-element analysis. This paper aims to evaluate the corrosion behaviour of austenitic stainless steel type 304 in a chloride solution in the presence of elastic zone stress by potentiodynamic measurement tests.

\section{METHODS AND MATERIALS}

\section{Experimental Set Up}

The methodology of this research work aims to study the Experimental Procedures. The specimens were formed into C-ring shapes according to the ASTM G-38 Standard [13] (as shown in Figure 1) and were used in the experimental setup. In which $O D_{f}$ is the outside diameter after stressing, $f$ is the desired stress, $\Delta$ is the deflection of the $O D$ given by the desired stress, $D$ is the mean diameter equal to $O D$ - thickness. The surface model was selected based on actual problems that frequently occur on aircraft wings [14], helicopter longerons [15] and petrochemical storage tanks. This type of loads (compression) was explored to evaluate the model. 


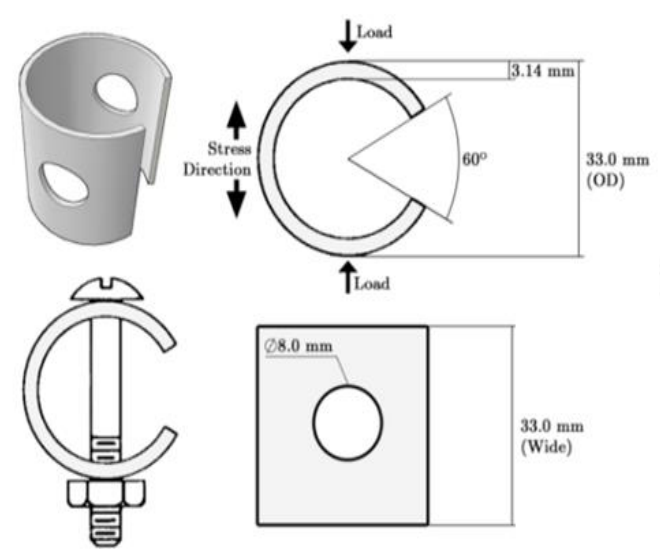

(a) Size and shape of the specimen used based on the ASTM G38 standard
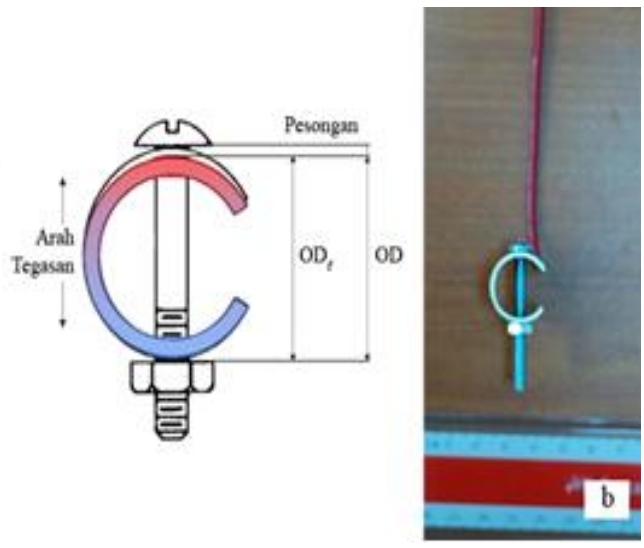

(b) Illustrates the loading mechanism and the actual image of the specimen used.

Figure 1. Specimen used based on the ASTM G38 standard.

\section{Experimental Procedures and Material Used}

The specimens and the experimental setup for the $\mathrm{C}$-ring are explained in this sub-section. The material used for the experiments was 304 steel, which was selected because it had been previously used for industrial applications (such as in aircraft) over the last 40 years. The chemical composition of this material includes $\mathrm{C}(0.75$ weight $\%)$, Si (0.36 weight $\%)$, Mn (0.26 weight\%), P (0.018 weight $\%), \mathrm{S}$ (0.010 weight\%), Cr (3.30 weight\%), Ni (0.12 weight $\%$ ) and Mo (4.50 weight $\%$ ). The specimen surface was mechanically polished with P120, P600 and P2000 grit papers and then followed by rinsing with distilled water. The specimens were formed into C-ring shapes according to the ASTM G-38 Standard, as shown in Figure $1(\mathrm{a}, \mathrm{b})$. The specimens for the electrochemical tests were machined carefully to the C-ring shape and coated with silicone adhesive. The exposed area was 1.0 $\mathrm{cm}^{2}$ as a working electrode (WE). Figure 1 shows the shape, the mechanical load model, including the stress direction and the dimensions of the sample.

Based on the standard of the SCC specimen, the stress is calculated by reducing the thickness as it is expressed as follows [13]:

$$
\begin{gathered}
O D_{f}=O D-\Delta \\
\Delta=f \pi D^{2} / 4 E t Z
\end{gathered}
$$

where $O D_{f}$ is the outside diameter after stressing, $\mathrm{f}$ is the desired stress, $\Delta$ is the deflection of $O D$ given by the desired stress, $D$ is the mean diameter equal to $O D$ thickness, $E$ is the modulus of elasticity, and $Z$ is a correction factor for curved beams as shown in Figure 2 (available in ASTM) [13]. Since the deflection is a parameter as an input set of data, using Equation (2), the scale of deflection used to obtain the stress in the specimen was calculated by:

$$
f=\frac{\Delta \times 4 E t Z}{\pi D^{2}}
$$


The C-ring samples, as generally used, are a constant-strain specimen. The tensile stress is produced on the exterior of the ring by tightening a bolt centred on the outside diameter $(O D)$. The level of stress is described by adjusting the outside diameter of the samples. To predict the desired stress, the compression tests were conducted on the Cring sample.

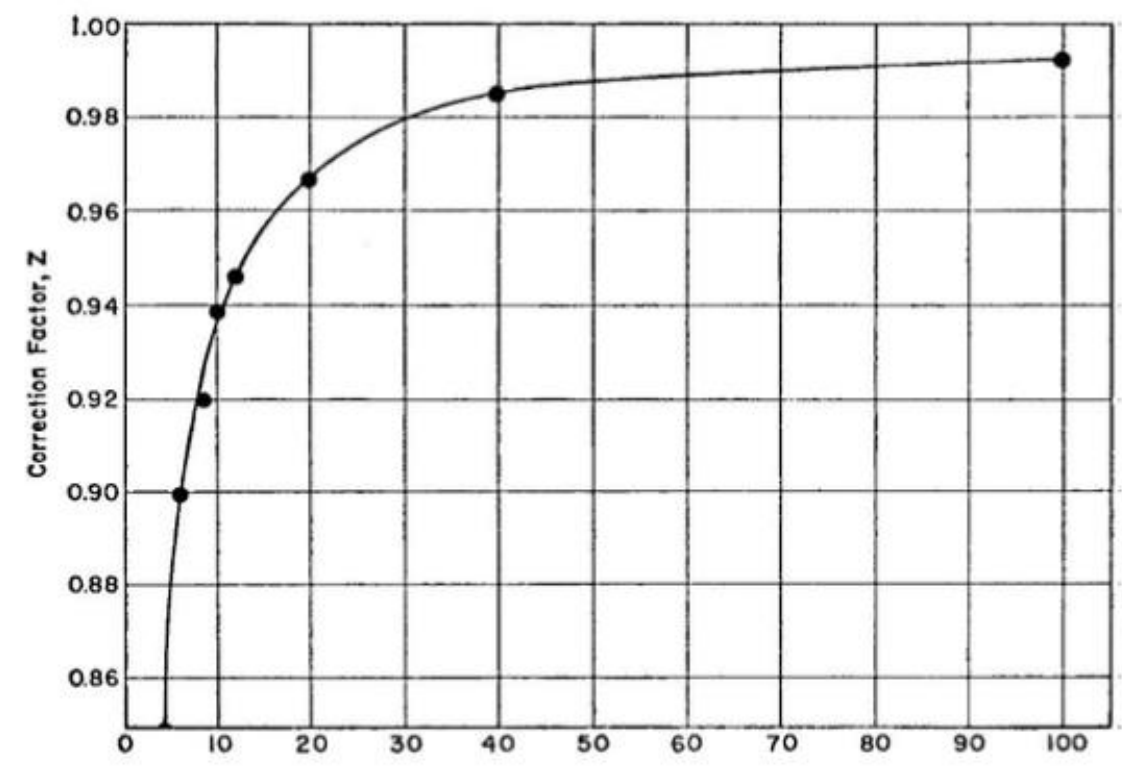

Figure 2. Corrosion factor for curve [13].

The compression test was carried out to obtain the yield point of the specimen. Based on the compression test result, three levels of deflection are specified with reference to the samples. The finite element approaching is conducted to estimate the desired stress during loading by deflection. The results of the estimated stress are used to obtain the relation of corrosion behaviour and stress during the applied load. A commercial finite element analysis Abaqus ${ }^{\text {TM }} 6.11$ was implemented for this study. The model for the finite element analysis follows the dimension and material properties of the actual sample. This approach seeks to obtain the relevance of the polarisation curve and each level of stress.

\section{Method of electrochemical measurements}

Many complex electro- chemical reactions occurred; the polarisation character is the reflection of these reactions. Stress level which is only the variable will affect the polarisation response the degree of stress in the specific corrosive environmental due to the magnitude of stress. The polarisation data will be used to solve the model later. To keep the effects of polarisation and in turn, to be able to estimate the grade of corrosion that occurred with the specimens, it was necessary to build up a set of electrochemical measurement equipment. The ASTM G-108 was used as a reference for obtaining the answers. The ASTM G-108 standard describes the steps that must be implemented in order to conduct the electrochemical measurement of the SUS 304 stainless steel specimens. The electrochemical measurements were done using samples with a 10x10 $\mathrm{mm}$ working area. The trials were also taken for a $3.5 \% \mathrm{NaCl}$ solution at room temperature. The working electrode (WE) was the sample material and the reference electrode was $\mathrm{Ag} / \mathrm{AgCl}$ (Silver Chloride Electrode). 


\section{Immersion method}

Three immersion times were used to assess the changes in polarisation. For this goal, the ASTM G44 standard was used as a guide in making artificial seawater. $3.5 \% \mathrm{NaCl}$ (Sodium Chloride) was added to the required quantity of distilled water. Figure 3 shows the exposed area on the specimen and the concentration of the specimens in the $3.5 \%$ $\mathrm{NaCl}$ solution. Furthermore, in order to obtain an appropriate field of vulnerability on the specimen, a protective coating process was carried out using isolators. The exposed part of the specimen was only opened as wide as $10 \mathrm{~mm}^{2}$ in the area estimated to receive the highest levels of stress. The final stage of the specially made salt bridge was aimed straight at the exposed area on the specimen. Figure 3(b) shows the exposed area on the specimen and the immersion of the specimens into the $3.5 \% \mathrm{NaCl}$ solution.
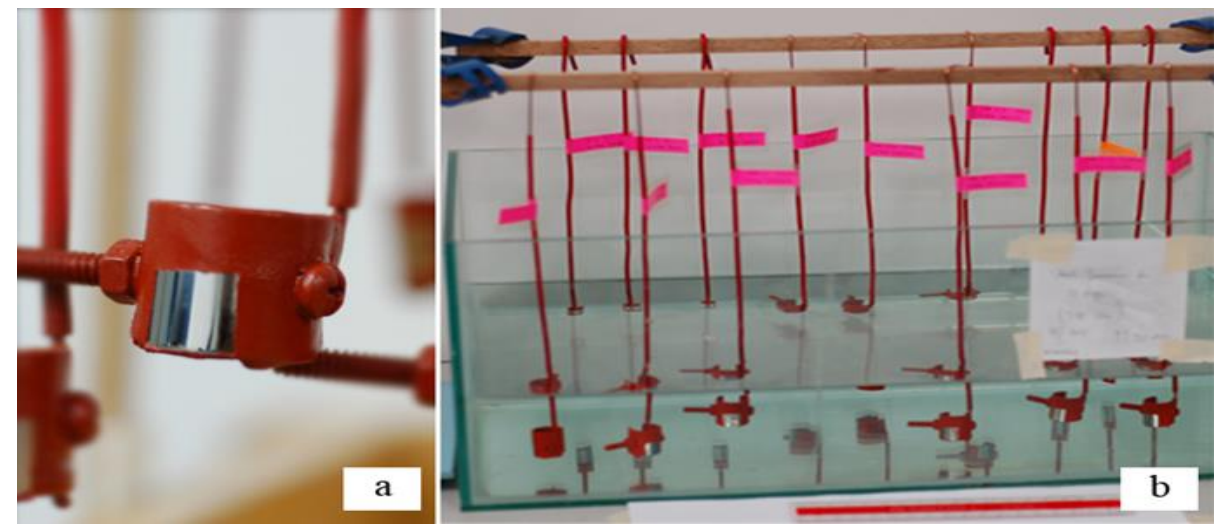

Figure 3. (a) Specimen with a $1 \mathrm{~cm}^{2}$ area of exposure, and (b) Immersion of the specimens in the container.

\section{Specimen, Solution and Surface Preparation}

The samples were prepared according to the ASTM G-38 Standard. Austenitic stainless steel type 304 has been chosen due to its extensive usage in manufacturing industries. Table 1 shows the chemical composition and mechanical properties of austenitic stainless steel type 304. C-ring specimens as the Working Electrode (WE) for the electrochemical test were machined accurately in order to avoid effect of surface roughness during electrochemical measurements $([16,17]$. The specimens were coated using silicone metal after the electric connector was installed. Before the immersion time began, the constant load was applied to the specimens.

Table 1. Composition of 304 stainless steel.

\begin{tabular}{lr}
\hline Composition & \% (by weight) \\
\hline $\mathrm{Fe}$ & 71.50 \\
$\mathrm{C}$ & 2.86 \\
$\mathrm{Cr}$ & 15.83 \\
$\mathrm{Ni}$ & 7.02 \\
$\mathrm{Mn}$ & 2.80 \\
\hline
\end{tabular}

Commercial austenitic stainless steel type 304 was used for all experiments with nominal composition, as shown in Table 1. Prior to the corrosion measurement, the specimens were wet-ground from P120, P600 to P2000 grit paper, followed by rinsing 
with distilled water. The C-ring specimens as WE were received in a state following the ASTM G-38 standard to represent the constant load condition. The exposed area at the surface of the WE was $1.0 \mathrm{~cm}^{2}$. Figure 4 shows the shape of the specimen, the mechanical load model and the dimensions of the WE. All electrochemical tests were conducted in $3.5 \%$ wt of $\mathrm{NaCl}$ at room temperature $\left(25^{\circ} \mathrm{C}\right)$ and immersed for 720 hours. In order to determine the yield stress of the material, compression tests were carried out on the $\mathrm{C}$ ring specimen. Compression test results predict the relation between deflection and the value of load. Based on the compression test result, the maximum value in the elastic zone of the C-ring specimen was measured at $0.7 \mathrm{~mm}$ deflection. This value was selected as the maximum load for the C-ring specimen. To estimate the desired stress, a finiteelement analysis was conducted based on the deflections from the compression test.

The estimation of stress on the surface of the C-ring specimen was conducted using the finite-element analysis. The visualisation of stress using the finite-element analysis illustrated the gradient of stress levels on the surface of the C-ring specimen. Therefore, the exposed area for the polarisation measurement could be determined at the highest area of stress. The model for the finite element analysis uses a similar shape of the specimen for the electrochemical experiment. Other parameters, such as dimension, material properties and the deflection of the applied load are based on the actual specimens.
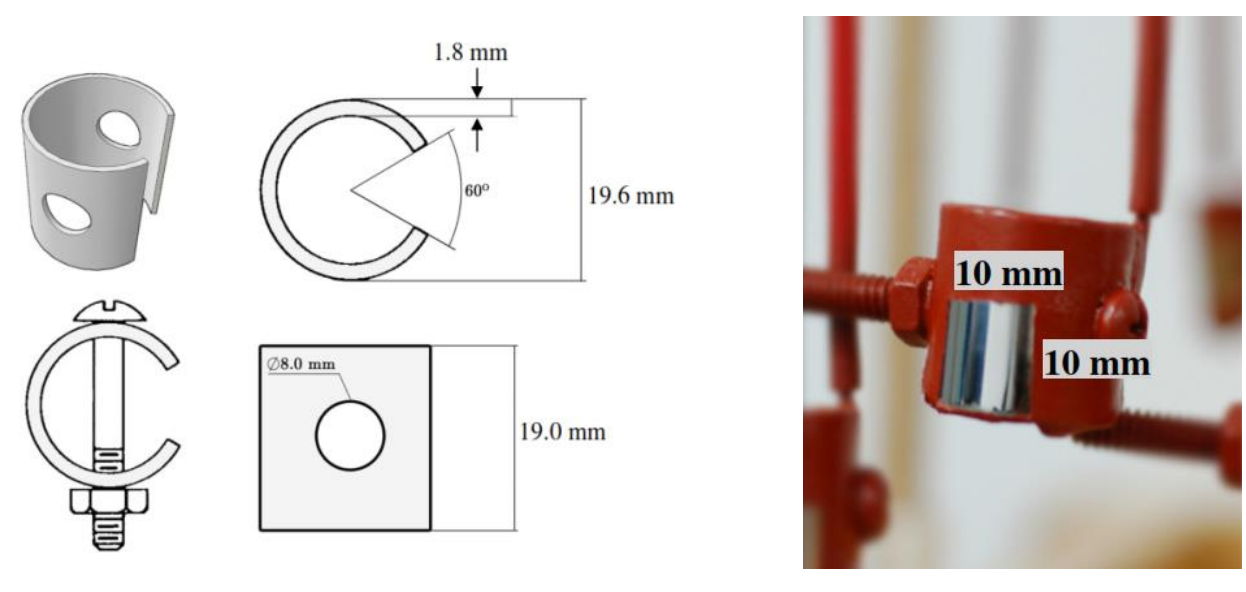

Figure 4. The specimen dimension, constant load model and surface area.

\section{Electrochemical Measurement}

The electrochemical measurements were performed using samples with $1.0 \mathrm{~cm}^{2}$ of the working area exposed to $3.5 \mathrm{wt} . \%$ of $\mathrm{NaCl}$. A portable model of the Potentiostat type ZIVE PP1 (Korea) connected to an electrochemical cell was used for measurements. The C-ring specimen was the working electrode (WE). A Silver Chloride Electrode $(\mathrm{Ag} / \mathrm{AgCl})$ was used as the Reference Electrode (RE) and a graphite bar was prepared as the Counter Electrode (CE). The potentiodynamic polarization measurement began at the natural potential of the specimen (Restpot) nearest to the $-1000 \mathrm{mV}$ increment under the restpot. Proceed through $1000 \mathrm{mV}$ above respot versus the silver chloride electrode. The potential sweep rate for the potentiodynamic method is $0.6 \mathrm{~V} / \mathrm{h}(5 \%)$ recording the current continuously with a change in potential from $-1000 \mathrm{mV}$ of the restpot. This means that the measurement began from the noble to the active area. The specific configuration parameters for these measurements are shown in Table 2. 
Table 2. Potentiodynamic scan configuration.

\begin{tabular}{ll}
\hline Software & LAB View and IVMAN 1.1 \\
& Electrochemical Workstation \\
Hardware & ZIVE PP1 (Korea) \\
Filter & $60 \mathrm{~Hz}$ \\
Type of Scan & Potentiodynamic \\
Reference Electrode & SSE (Silver Chloride Electrode) \\
Step Increment & $1 \mathrm{mV}$ \\
Scan Rate & $0.6 \mathrm{mV} / \mathrm{s}$ \\
\hline
\end{tabular}

\section{RESULTS AND DISCUSSION}

\section{Stress Analysis}

The experiments start with a compression test to obtain the relation of deflection and load, as shown in Figure 5. The result of the compression test was used to measure the yield strength of the C-ring specimen. The maximum deflection value for the $\mathrm{C}$-ring specimen was estimated at $0.7 \mathrm{~mm}$. This number was applied to input the value of displacement for the finite element analysis. The finite element analysis resulted in the distribution of stress on the surface of the $\mathrm{C}$-ring model. Table 3 shows the relationship between the deflection of $O D$, the applied load for the C-ring and the estimated stress on the exposed area.

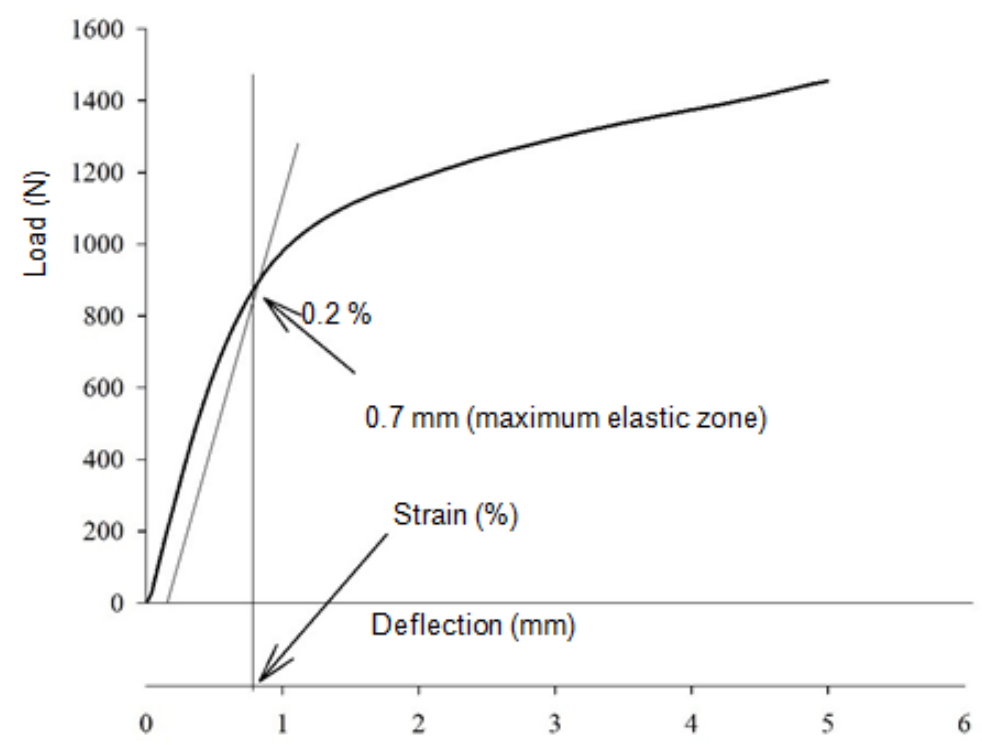

Figure 5. Estimation of yield strength by using a compression test for the C-ring shape specimen.

Table 3. Deflection by loading.

\begin{tabular}{cccc}
\hline Type & $\begin{array}{c}\text { OD Deflection } \\
(\mathrm{mm})\end{array}$ & Load $(\mathrm{N})$ & $\begin{array}{c}\text { Maximum Stress at } \\
\text { exposure area }(\mathrm{MPa})\end{array}$ \\
\hline Load 1 & 0,3002 & 402.999 & 197.199 \\
Load 2 & 0.5003 & 640.226 & 328.665 \\
Load 3 & 0.7001 & 819.021 & 460.131 \\
\hline
\end{tabular}


Figure 5 shows that the maximum of the elastic point for the $\mathrm{C}$-ring sample is at a $0.7 \mathrm{~mm}$ deflection. This number is applied as the maximum load for the C-ring sample. The relationship between deflection and the stress applied to the C-ring specimen was obtained through simulation. The use of the finite element method on the C-ring specimen model was performed using the Abacus software. The results from the simulation calculations were plotted into a graph that showed the relationship between the applied deflection and the stress that occurred on the surface of the specimen. The region that was studied was the surface of the C-ring specimen that was exposed to the environment in the polarisation experiment. This simulation study was conducted to observe the stress distribution that occurred in the exposed region on the C-ring specimen. This was necessary because the focus of the study was on the region that was exposed to the environment during the measurement of polarisation and its relationship with the stress that occurred in the region concerned.

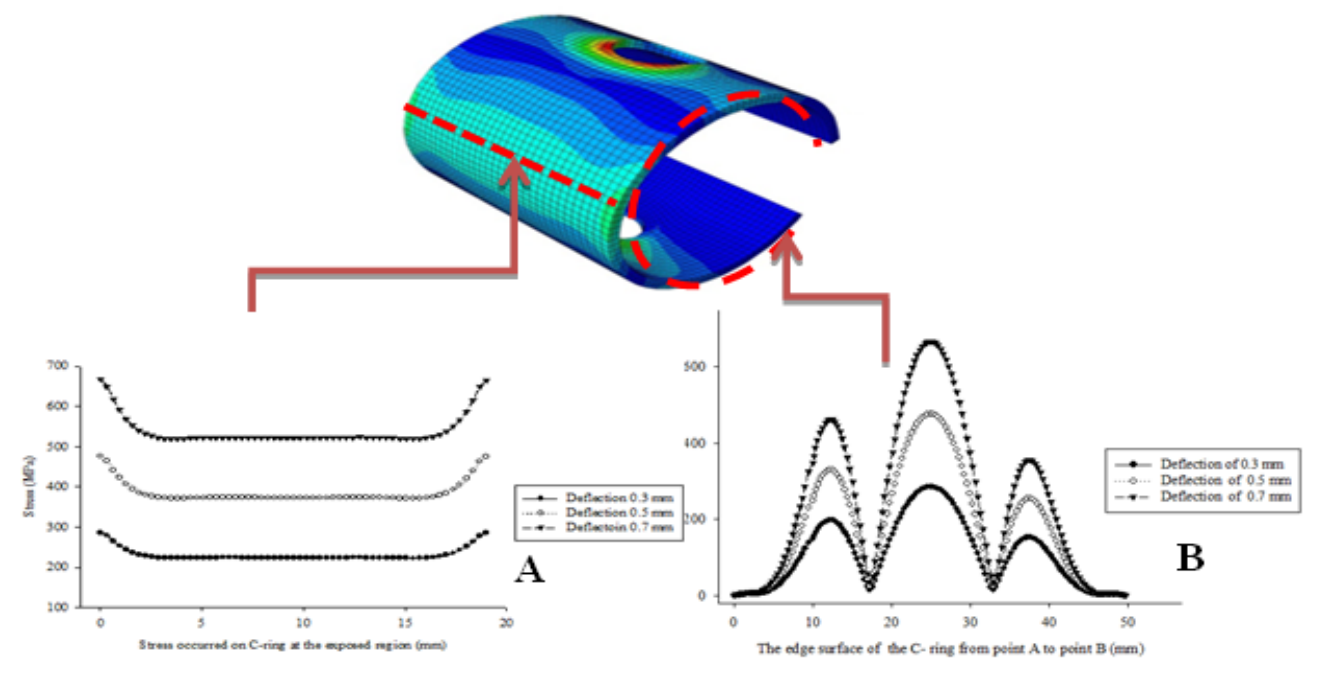

(a)Stress distribution at perpendicular to the deflection.

(b) Stress distribution at the edae of the samble.

Figure 6. Stress distribution on the surface area of the C-ring shape.

The simulation results showed that the highest stress experienced by the specimen was at the side of the C-ring surface, while the middle of the C-ring experienced a lower stress. Figures 6 and 7 show the stress distribution during the deflection that was applied to the C-ring model. Three levels of deflection were applied to observe the stress that occurred. A straight line was drawn on the surface of the C-ring to mark the stress distribution on the surface. This line was in the area perpendicular to the direction of the applied load. Figure 6 shows the exposed region, which indicated the stress distribution throughout the surface of the C-ring specimen, while the stress in the form of a graph at the line in the exposed region is presented in Figure 7.

Figure 7 shows the region that was subjected to the highest load, namely the region where the shift in the direction of the pressure on the model occurred. Nevertheless, the region did not fall within the scope of this study because it was not within the exposed region of the polarisation experiment. Thus, the exposed region in the polarisation experiment was the region that was perpendicular to the shift in the direction of the 
pressure. This method referred to the ASTM G-38, which describes the corrosion experiment for the C-ring specimen.

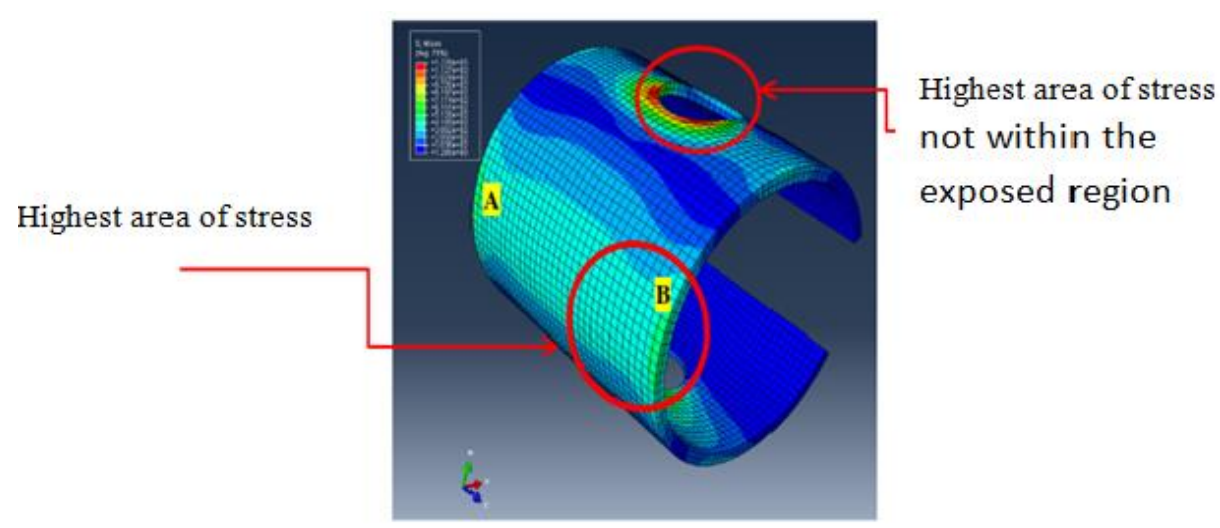

Figure 7. Highest stress area of C-ring model.

\section{Polarisation Behaviours}

Two polarisation curves were generated for a specimen at zero stress as shown in Figure 8. There are significant differences between the two polarisation curves. The immersed curve indicates stability in the current density proportional to the non-immersed specimen. The differences of the current curve in the anodic region indicate the immersion of the specimen influence to the anodic reaction. Due to the anodic and the cathodic potential-current density relationship not being quite symmetric, the condition known as faradaic rectification is presented (Butler et al., 2013)[18]. Figure 8 also shows the corrosion potential vs. the current density for 304 stainless steel at zero stress with two treatments: immersed for 720 hours (30 days) in a $\mathrm{NaCl}$ solution and a non-immersed specimen.

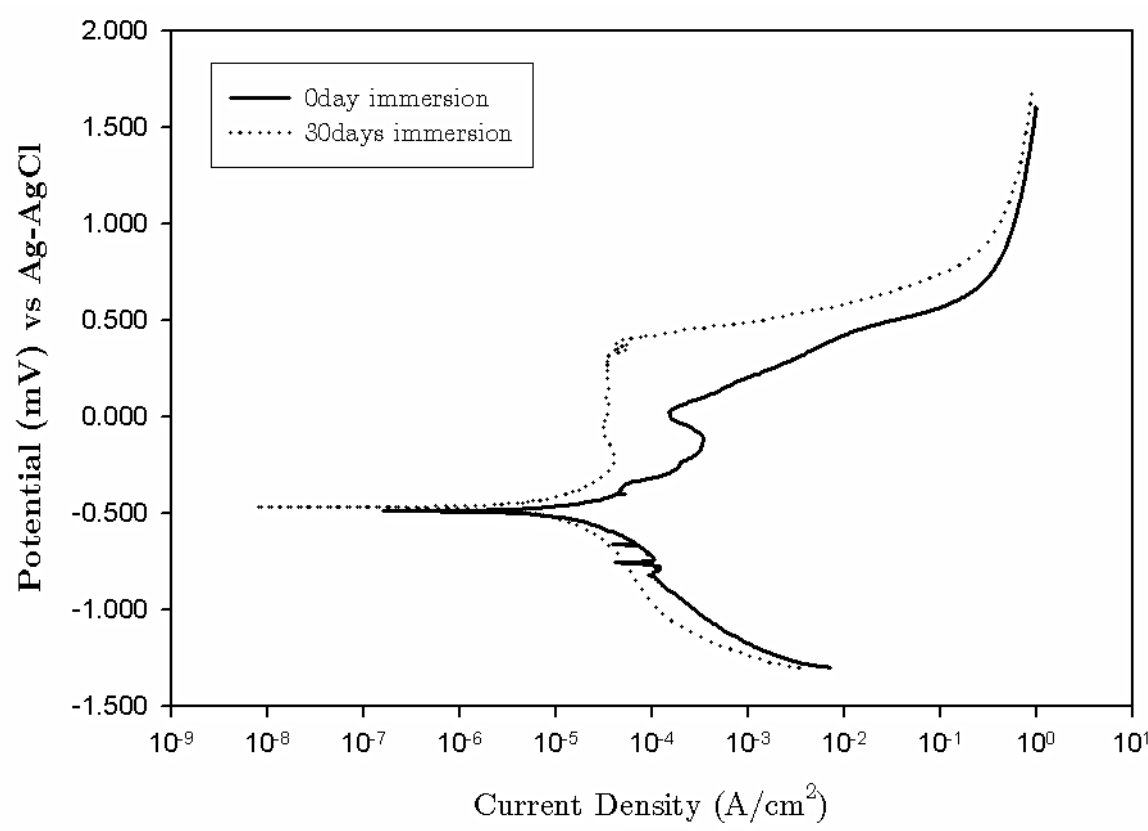

Figure 8. Polarisation curve of stainless steel 304 at $3.5 \% \mathrm{NaCl}$ for zero day and 720 hours Polarisation Curve at zero stress. 
The curve of the non-immersed specimen shows the corrosion potential (Ecorr) at $-533.503 \mathrm{mV}$ and the (Icorr) at the current density in these conditions were $6.183 \mu \mathrm{A}$. Anode polarisation curves under these conditions show a region of passivation at $0.05 \mathrm{~V}$, which indicates the passive layer on the surface of stainless steel damage after passivation. Meanwhile, the samples that have been immersed for 720 hours in a solution show that the polarisation results were almost identical at the cathodic region but absolutely different at the anodic region. The stability of current density in the anodic region indicates the immersion of specimen makes no occurrence of passivation and the pitting corrosion appears after $0.320 \mathrm{mV}$ the rate of corrosion was influenced by level of stress [12]. Both of polarisation curves show the different corrosion potential and different point at initiation of pitting corrosion. However, the value of Icorr which influence to the corrosion rate the immersed specimen and non-immersed specimen identified at $6.183 \mu \mathrm{A}(6.2 \times 10-6 \mathrm{~A} / \mathrm{cm} 2)$ and $6.232 \mu \mathrm{A}(6.2 \times 10-6 \mathrm{~A} / \mathrm{cm} 2)$ respectively. This contiguous value of Icorr realised the contiguous of corrosion rate (CR) which 2.501MPY for non-immersed specimen and 2.521MPY for 30 days immersion specimen.

Based on the corrosion rate of both samples without mechanical loading, there is no significant influence of the immersion time for the behaviour of polarisation corrosion. The difference of the Icorr value was strongly affected to the corrosion rate, as shown in Figure 9. The corrosion rate by the highest stress reached 94.100 MPY for the immersed sample for 720 hours. The corrosion rate by the highest stress reached 94.100 MPY for the immersed sample for 720 hours. It is strongly different compared to another sample with different stress and which was similarly immersed into the solution.

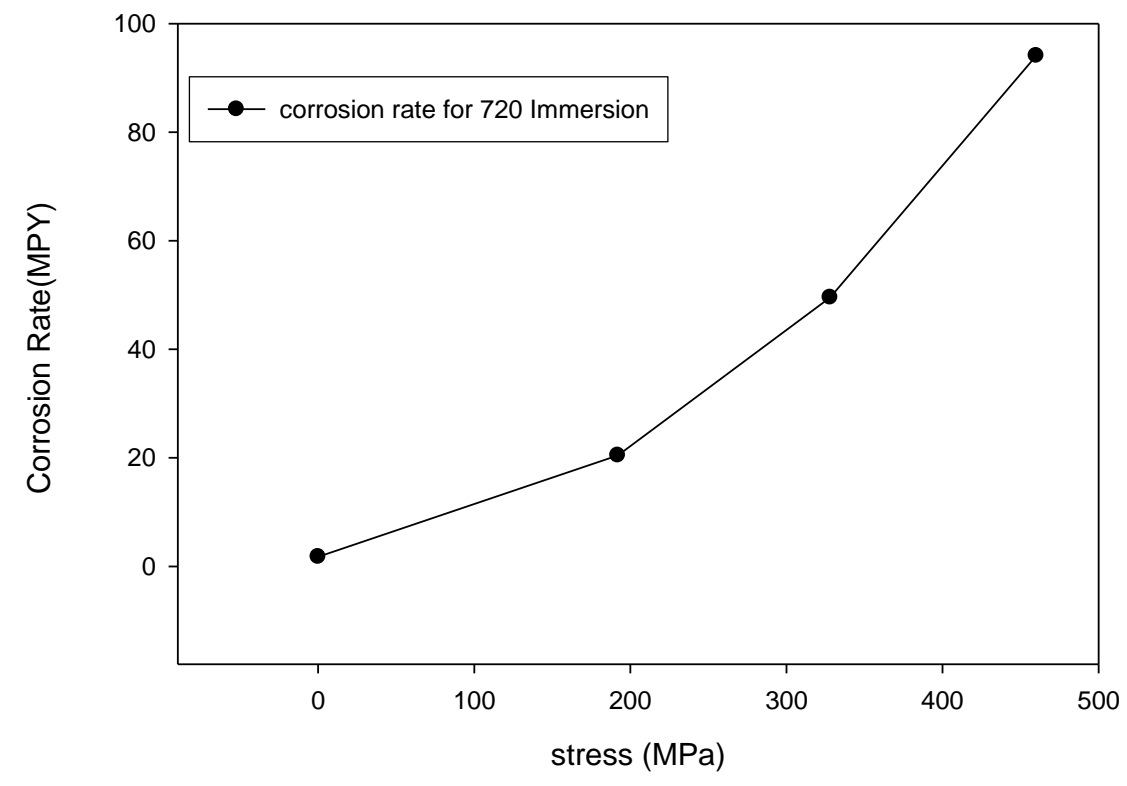

Figure 9. Relation of stress and corrosion rate.

Figure 10 showed the effects of stress on the corrosion damage shown by the polarisation behaviour of the C-ring specimen. The impact of stress is clearly identified in the samples that have been immersed for 720 hours. The value of the current density was identified at $232 \mu \mathrm{A}$, and the corrosion potential at $-0.889 \mathrm{~V}$. This number indicated the material was in a high risk condition for corrosion damage. By using the extrapolation Tafel method, the corrosion rate was rated at 94 mili-inch per year (MPY). The corrosion reaction indicated increased corrosion in the environment with $\mathrm{NaCl}$. These effects are 
due to the chloride ions penetrating the passive film of stainless steel [19]. This reaction causes film breakdown and initiates the corrosion damage of the material. The stress concentration on the surface of the stainless steel causing pitting corrosion started in this area, as it is seen by the appearance of the pitting corrosion that occurred more frequently in the analysed area compared to other regions [20]. The polarisation behaviour shows that the effect of stress concentration contributed initiating the pitting corrosion.

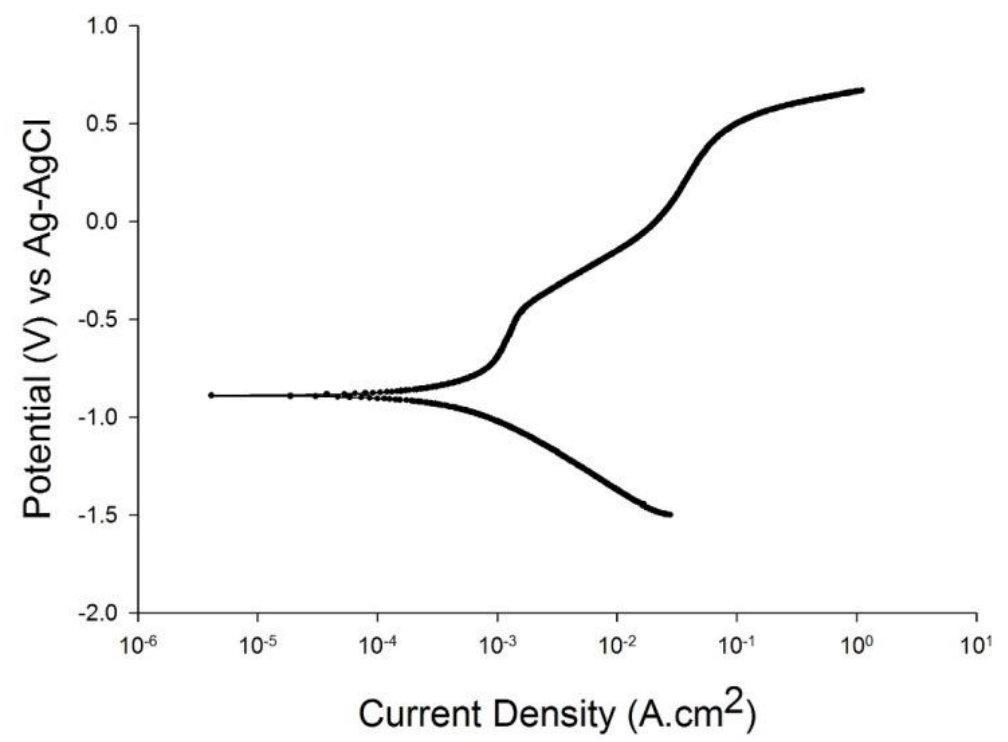

Figure 10. Polarisation curve of austenitic stainless steel during pitting corrosion under stress.

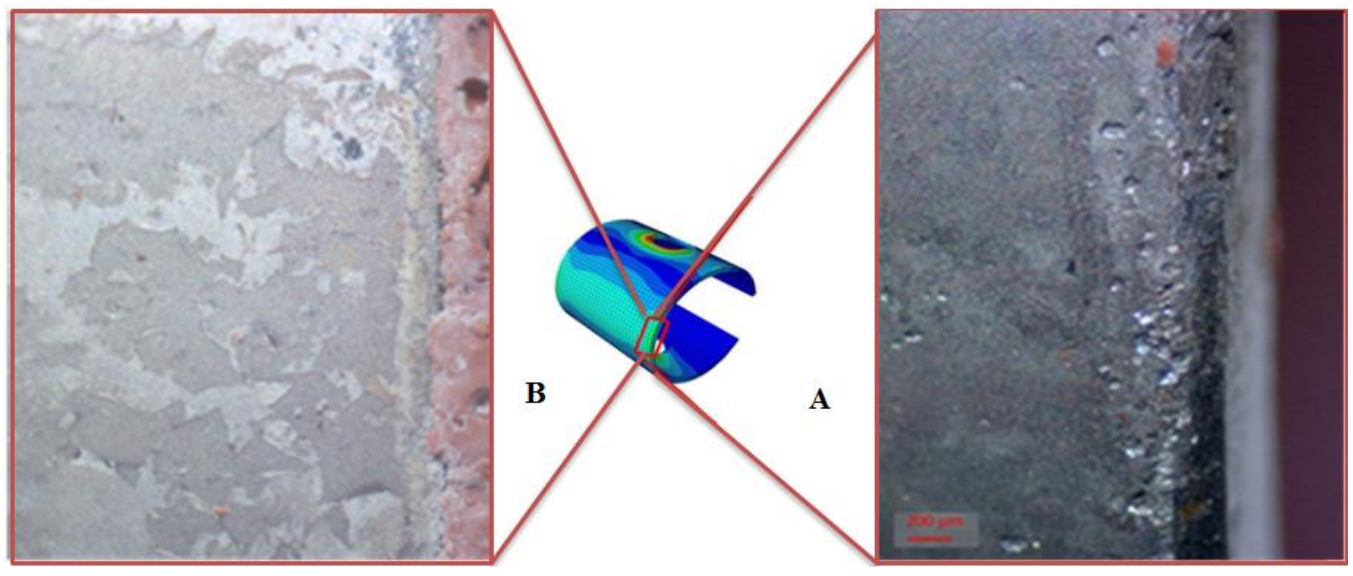

Figure 11. (A) The pitting corrosion distribution on the edge of the C-Ring surface; (B) The edge of the C-Ring surface under less stress.

To determine the location of the pitting corrosion at the highest stressed area, an optical observation was applied on the surface of the C-ring specimen. Figure 11(A) shows the region of stress and the pitting corrosion on the surface of austenitic stainless steel, and Figure 11(B) shows the same region of stress and the no pitting corrosion on the surface of austenitic stainless steel for an area exposed to less stress, as can been seen in Figure 11. By using optical observation, the pitting corrosion damage clearly appears 
on the edge of the C-ring specimen surface. This is related to the result of the finiteelement analysis. The area of the pitting corrosion is correlated with the highest area of stress as shown by the finite-element result.

\section{CONCLUSIONS}

Many hypotheses of the corrosion damage on the stainless steel in sodium chloride have been confirmed, particularly for 304 austenitic stainless steel. The elastic zone stress under the yield strength of this material contributed to the pitting corrosion in cases when immersion and stress are applied simultaneously. The essential factor for decreasing the corrosion behaviour of 304 stainless steel is the level of stress during the applied load. The immersion time is not strongly affected by the corrosion behaviour of non-stressed material. The pitting corrosion triggered by stress occurred on the critical surface of austenitic stainless steel. Corrosive environments, such as seawater or sodium chloride solutions, drove the corrosion behaviour to a critical condition. The location of stress influenced the mechanism of the corrosion polarisation. The 94 MPY of the corrosion rate shows that the effect of stress could be critical if austenitic stainless steel is found in a corrosive environment.

\section{ACKNOWLEDGEMENTS}

The authors would like to be obliged to Universiti Kebangsaan Malaysia for providing laboratory facilities and financial support under project ERGS/1/2012/TK01/UKM/01/1.

\section{REFERENCES}

[1] Jamil WNM, Aripin MA, Sajuri Z, Abdullah S, Omar MZ, Abdullah MF, et al. Mechanical properties and microstructures of steel panels for laminated composites in armoured vehicles. International Journal of Automotive and Mechanical Engineering. 2016;13:3742-53.

[2] Ishak M, Shah LH, Aisha ISR, Hafizi W, Islam MR. Study of resistance spot welding between AISI 301 stainless steel and AISI 1020 carbon steel dissimilar alloys. Journal of Mechanical Engineering and Sciences. 2014;6:793-806.

[3] Gebril MA, Aldlemey M, Haider FI, Ali N. Effect of Austenizing and Tempering Time on Corrosion Rate of Austenitic Stainless Steel in Oxalic Acid. Advanced Materials Research: Trans Tech Publ; 2014. p. 46-51.

[4] Paredes E, Bautista A, Álvarez SM, Velasco F. Influence of the forming process of corrugated stainless steels on their corrosion behaviour in simulated pore solutions. Corrosion Science. 2012;58:52-61.

[5] Shah LH, Akhtar Z, Ishak M. Investigation of aluminum-stainless steel dissimilar weld quality using different filler metals. International Journal of Automotive and Mechanical Engineering. 2013;8:1121-31.

[6] Shah LH, Mohamad UK, Yaakob KI, Razali AR, Ishak M. Lap joint dissimilar welding of aluminium AA6061 and galvanized iron using TIG welding. Journal of Mechanical Engineering and Sciences. 2016;10:1817-26.

[7] Haque MM, Alam Limon S, Moniruzzaman M, Bepari MMA. Corrosion Comparison of Galvanized Steel and Aluminum in Aqueous Environments. International Journal of Automotive and Mechanical Engineering. 2014;9:175867. 
[8] Buang MS, Abdullah SA, Saedon J. Effect of die and punch radius on springback of stainless steel sheet metal in the air V-die bending process. Journal of Mechanical Engineering and Sciences. 2015;8:1322-31.

[9] Abd Razak NA, Ng SS. Investigation of effects of MIG welding on corrosion behaviour of AISI 1010 carbon steel. Journal of Mechanical Engineering and Sciences. 2014;7:1168-78.

[10] Ashraf M, Gardner L, Nethercot D. Compression strength of stainless steel crosssections. Journal of Constructional Steel Research. 2006;62:105-15.

[11] Badea G, Caraban A, Sebesan M, Dzitac S, Cret P, Setel A. Polarisation measurements used for corrosion rates determination. Journal of Sustenable Energy. 2010;1-4.

[12] Rashid S, Islami N, Ariffin A, Ridha M. The effect of immersion time on the corrosion behavior of SUS304 in brine using half-cell potential measurement. Jurnal Teknologi. 2016;78:91-9.

[13] Sandrea R. An in-depth view of future world oil and gas supply-A production capacity model. Penn Energy Research. 2010.

[14] Iyyer N, Sarkar S, Merrill R, Phan N. Aircraft life management using crack initiation and crack growth models-P-3C Aircraft experience. International Journal of Fatigue. 2007;29:1584-607.

[15] Kapoor R, Rao VSH, Mishra RS, Baumann JA, Grant G. Probabilistic fatigue life prediction model for alloys with defects: applied to A206. Acta Materialia. 2011;59:3447-62.

[16] Du X, Su Y, Li J, Qiao L, Chu W. Stress corrosion cracking of A537 steel in simulated marine environments. Corrosion Science. 2012;65:278-87.

[17] Asmara Y, Siregar J, Shah L, Tezara C. Experimental Investigations on Corrosion Model of Welded 6061 Aluminum Exposed in $\mathrm{NaCl}$ Solution. International Journal of Automotive and Mechanical Engineering. 2015;11:2600.

[18] Butler BM, Chopra MB, Kassab AJ, Chaitanya V. Boundary element model for electrochemical dissolution under externally applied low level stress. Engineering Analysis with Boundary Elements. 2013;37:977-87.

[19] Olsson CO, Landolt D. Passive films on stainless steels - chemistry, structure and growth. Electrochimica Acta. 2003;48:1093-104.

[20] Alvarez RB, Martin HJ, Horstemeyer M, Chandler MQ, Williams N, Wang PT, et al. Corrosion relationships as a function of time and surface roughness on a structural AE44 magnesium alloy. Corrosion Science. 2010;52:1635-48. 